\title{
Evaluation of Corrosive Behavior of Four Nickel-chromium Alloys in Artificial Saliva by Cyclic Polarization Test: An in vitro Study
}

\author{
${ }^{1}$ Rubina Begum, ${ }^{2}$ Padma Ariga, ${ }^{3}$ Ashish R Jain
}

\begin{abstract}
Introduction: Dental casting alloys made of high noble alloys, noble alloys, and predominantly base metal alloys have been used in the fabrication of fixed and removable prosthetic dental appliances. Nickel-chromium ( $\mathrm{NiCr}$ ) alloy has been widely used in the fabrication of fixed and removable partial denture frameworks owing to its superior physical properties and lower cost, but their resistance to tarnish and corrosion is debatable.
\end{abstract}

Aim: The aim of this study is to evaluate and compare the corrosive behavior of four commercially available $\mathrm{NiCr}$ alloys with that of a high noble alloy.

Materials and methods: Four commercially available $\mathrm{NiCr}$ alloys (study groups) and high noble alloy were used to study the corrosion by cyclic polarization test, and the parameters that were evaluated are corrosion potential (Ecorr), breakdown potential $(E b)$, repassivation potential $(E p)$, and corrosion current (Icorr).

Results: When all the findings from the four parameters were evaluated, the values of the control group were significantly higher than the study groups, and among the four study groups, group III alloy was significantly more resistant to corrosion than the other alloy groups.

Conclusion: Within the base metal alloy study groups, group III behaves to be more resistant to corrosion. Both nickel and chromium ions were released during the corrosion process, but the percentage of nickel ions was relatively higher than chromium ions.

Clinical significance: With the advent of new dental alloys in the market, the biocompatibility of dental materials is of critical concern and the evaluation of corrosive behavior of new dental alloys is highly warranted.

Keywords: Chromium, Corrosion, Cyclic polarization, Nickel, Noble alloy.

How to cite this article: Begum R, Ariga P, Jain AR. Evaluation of Corrosive Behavior of Four Nickel-chromium Alloys in Artificial Saliva by Cyclic Polarization Test: An in vitro Study. World J Dent 2017;8(6):477-482.

Source of support: Nil

Conflict of interest: None

${ }^{1-3}$ Department of Prosthodontics, Saveetha Dental College and Hospitals, Saveetha University, Chennai, Tamil Nadu, India

Corresponding Author: Ashish R Jain, Department of Prosthodontics, Saveetha Dental College and Hospital, Saveetha University, Chennai, Tamil Nadu, India, Phone: +919884233423 e-mail:dr.ashishjain_r@yahoo.com

\section{INTRODUCTION}

One of the most important factors affecting the choice of dental alloys is its biocompatibility and resistance to tarnish and corrosion. The metals and alloys which are to be used in oral cavity should withstand the moisture, temperature, and $\mathrm{pH}$ changes, which occur during the breakdown of foods. High noble alloys, noble alloys, and predominantly base metal alloys have been used in the fabrication of fixed and removable prosthetic dental appliances. The advantages of high noble and noble alloys include high resistance to tarnish and corrosion, and biocompatibility, and the major drawback of these alloys is their increased cost. ${ }^{1}$ To overcome the drawbacks, base metal alloys, such as cobalt-chromium and $\mathrm{NiCr}$ have been widely used in the fabrication of fixed and removable partial denture frameworks owing to their superior physical properties, such as high modulus of elasticity, thermal coefficient of thermal expansion matching with porcelain, high melting temperature withstanding high firing temperature without producing cracks, and lower cost, but their resistance to tarnish and corrosion is debatable. ${ }^{1-3}$ With the advent of new dental alloys in the market, the biocompatibility of dental materials is of critical concern, the evaluation of corrosive behavior of new dental alloys is highly warranted, and the purpose of this study is to evaluate and compare the corrosive behavior of four commercially available $\mathrm{NiCr}$ alloys with that of a high noble alloy as the control group in artificial saliva by cyclic polarization test and to analyze and authenticate the element released from four commercially available NiCr alloys by inductively coupled plasma mass spectrometer (ICP-MS).

\section{MATERIALS AND METHODS}

A sample die measuring $10 \mathrm{~mm} \times 10 \mathrm{~mm} \times 3 \mathrm{~mm}$ was machined in stainless steel (Fig. 1A). An addition of silicone impression (Aquasil Soft putty Regular set, Dentsply, Germany) was made from the sample die for the preparation of samples (working electrodes). Wax patterns were fabricated from the impressions using Inlay wax-medium (GC Corporation, Tokyo, Japan) and invested using phosphate-bonded investment (Bella Sun, Bego and Co., Germany). Four commercially available 

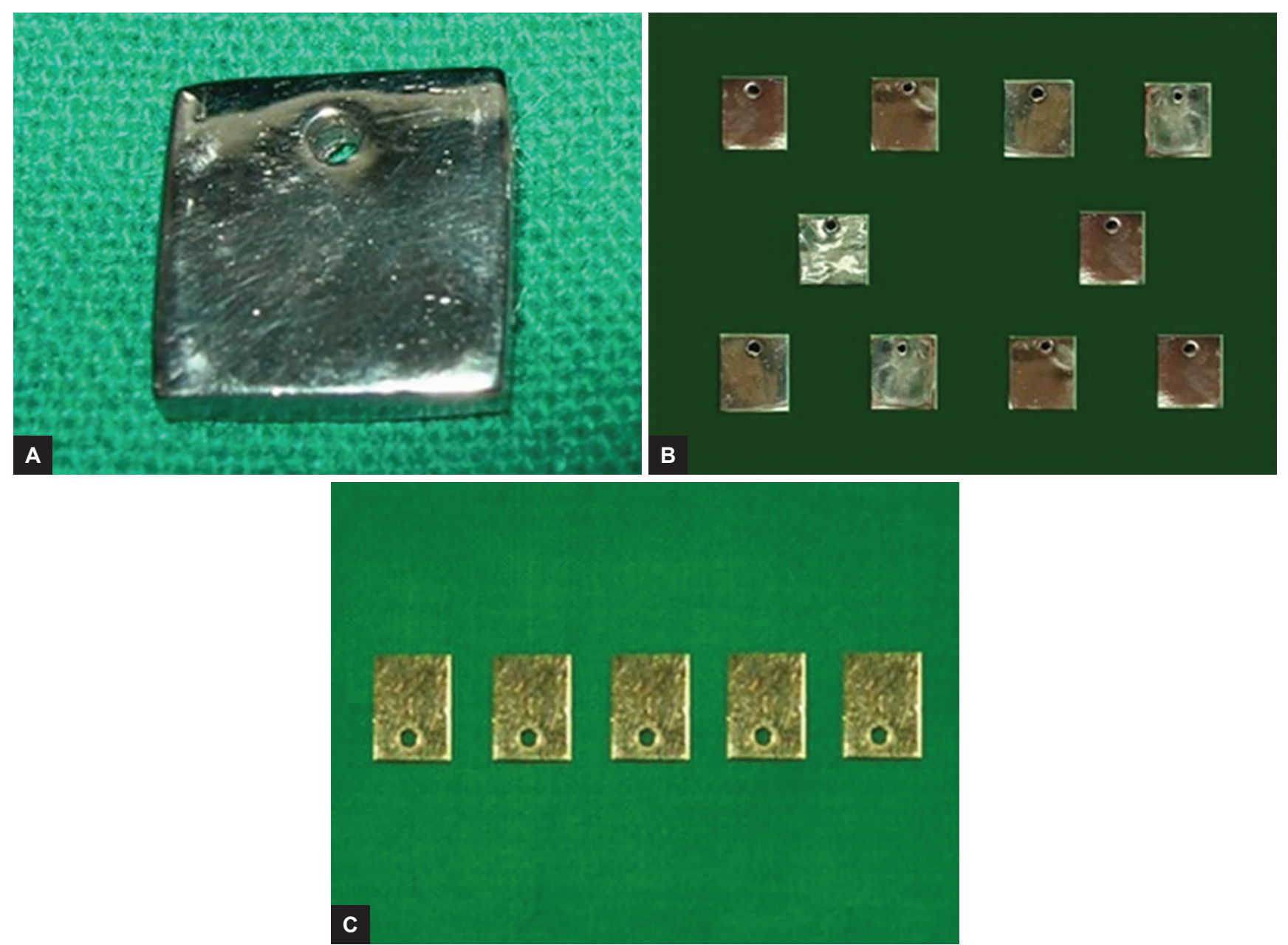

Figs 1A to C: (A) Machined sample die; (B) NiCr alloy samples; and (C) high noble alloy samples

NiCr alloys (Four all, Bellabond plus, Ceramet, and Heraenium) were used to cast the four groups of samples using induction casting machine (Fornax, Bego and Co.) (Fig. 1B and Table 1).

The control groups were of the same dimensions as the study groups (Fig. 1C). The samples working electrodes were mechanically polished using different grades of emery papers up to 800 grit papers and subsequently on a rubber polishing wheel and rouge. The samples working electrodes were then ultrasonically cleansed in acetone using digital ultrasonic cleanser (Unikleen) and thoroughly washed in distilled water. The surfaces of each sample working electrodes were visualized by Stereo Zoom Optical Microscope (UM1530R, Hong Kong) to ensure the uniformity of the

Table 1: Study groups taken in corrosion study

\begin{tabular}{ll}
\hline Study groups & Alloys used \\
\hline Group I & d-sign 98 (control group) \\
Group II & Ceramet \\
Group III & Four all \\
Group IV & Bellabond plus \\
Group V & Heraenium \\
\hline
\end{tabular}

surface before initiating the corrosion study. Current density of the samples' working electrodes per unit area was obtained by applying lacquer on one side so that only one side with $1 \mathrm{~cm}^{2}$ surface area was exposed on the other side and this formed the working electrode.

\section{Artificial Saliva Preparation}

The electrochemical cyclic polarization studies were carried out in artificial saliva electrolytes. Artificial saliva is freshly prepared each time for each sample working electrode. The composition of the artificial saliva used in the present study is given in Table 2. They are weighed in Electronic Balance Single pan-Dhona-260D.

Table 2: Composition of contents in artificial saliva

\begin{tabular}{ll}
\hline Sodium chloride & $0.4 \mathrm{gm}$ \\
Potassium chloride & $1.21 \mathrm{gm}$ \\
Sodium dihydrogen phosphate & $0.78 \mathrm{gm}$ \\
Sodium sulfide & $0.005 \mathrm{gm}$ \\
Urea & $1 \mathrm{gm}$ \\
Distilled water & $1000 \mathrm{~mL}$ \\
\hline
\end{tabular}




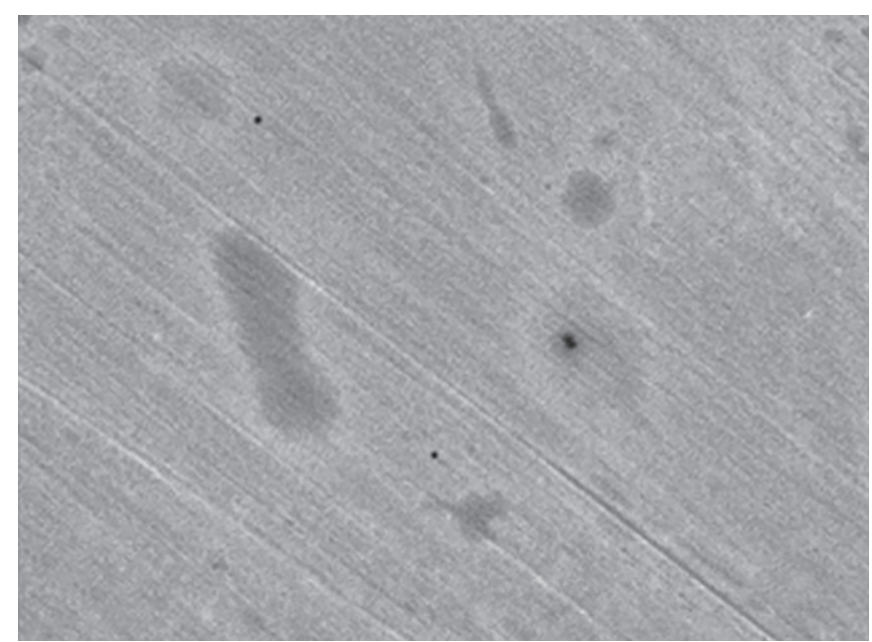

Fig. 2: Scanning electron microscope photomicrograph of group I

\section{Electrochemical Cell Assembly}

The electrochemical studies involving open circuit-time measurements and cyclic polarization measurements were carried out using a three-electrode cell assembly system of $500 \mathrm{~mL}$ capacities, potentiostat, and desktop with software attached. The electrodes are reference electrode, counter electrode, and working electrode.

\section{Cyclic Polarization Study}

The open circuit potential was monitored for each alloy sample. As soon as the sample was immersed in the electrolyte, the initial potentials of the specimens were noted and monitored as a function of time until a constant potential was reached and referred to as corrosion potential (Ecorr). All the alloy specimens were allowed to reach a steady open-circuit potential for a period of 1 hour. Cyclic polarization tests were conducted for each sample (working electrode) with a vibrant potentiostat/ galvanostat electrochemical interface controlled by commercial software. When the sample attained constant potential or steady state potential (Ecorr), cyclic polarization was initiated by applying a potential below the corrosion potential (Ecorr) and increased toward the positive direction at a scan rate of $1 \mathrm{mV} / \mathrm{cm}^{2}$, and scan (anodic scan) was continued until the threshold current density of $0.1 \mu \mathrm{A} / \mathrm{cm}^{2}$ was reached, during this period, the alloy entered the transpassive or pitting region named as breakdown potential (Eb), and then, the scan (cathodic scan) is reversed back to Ecorr of the alloy. The potential at which the reverse cathodic scan meets the forward anodic scan is termed the repassivation potential (Ep). The current density (Icorr) was monitored with respect to the potentials during polarization experiments.

\section{Accelerated Leaching Study}

One sample from each alloy was subjected to accelerated leaching study. The working electrodes were immersed

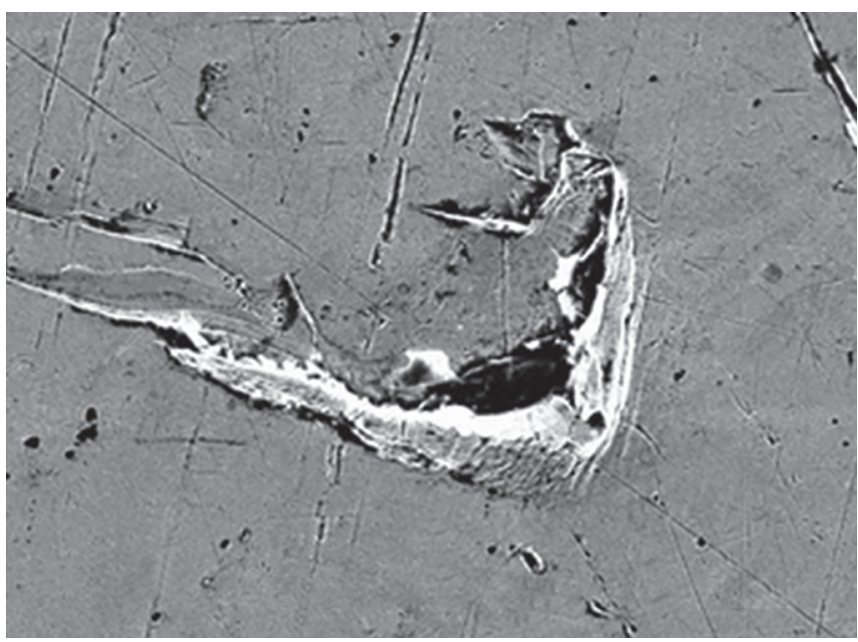

Fig. 3: Scanning electron microscope photomicrograph of group II

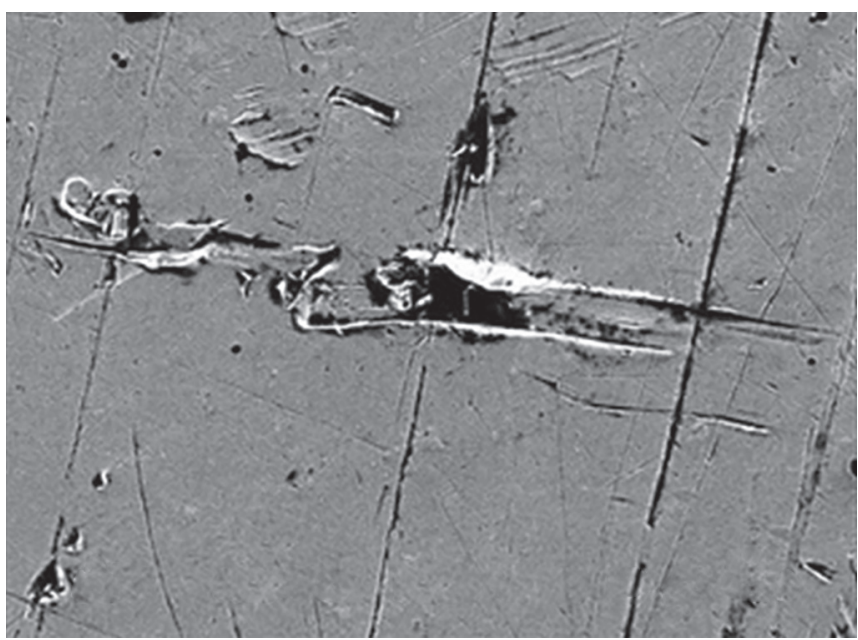

Fig. 4: Scanning electron microscope photomicrograph of group III

in artificial saliva and allowed to stabilize at corrosion potential (Ecorr) and breakdown potential (Eb) for a period of 1 hour in $250 \mathrm{~mL}$ of the test solution. At the end of each experiment, the chemical composition of the test solution was analyzed by ICP-MS.

\section{Scanning Electron Microscopic Study}

The surface morphology of the corroded samples was examined under scanning electron microscope (SEM) at $15 \mathrm{kV}$. The SEM photomicrographs were evaluated at $\times 1000$ magnification for all five groups (Figs 2 to 6 ).

\section{RESULTS}

In all the parameters studied (Ecorr, Eb, Ep, and Icorr), the values of the control group were significantly higher than the study groups. The mean absolute Ecorr value in control group $(-219.5 \pm 12.1)$ was significantly higher $(\mathrm{p}=0.0001)$ than in group II $(-161.8 \pm 9.4)$, group III $(128.3 \pm$ 12.0), group IV (-155.4 \pm 12.6$)$, and group V $(-119.3 \pm 13.4)$. The mean absolute Eb value in control group (1016.2 \pm 9.5$)$ 


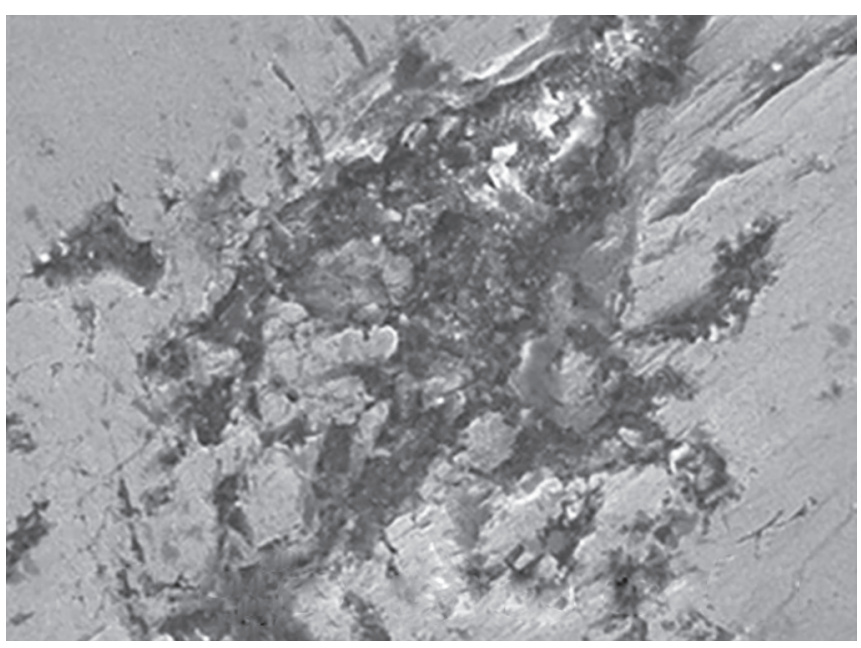

Fig. 5: Scanning electron microscope photomicrograph of group IV

was significantly higher $(\mathrm{p}=0.0001)$ than in group II (738.4 \pm 8.5$)$, group III $(800.1 \pm 6.7)$, group IV $(672.3 \pm 12.7)$, and group V (723.8 \pm 5.8$)$. The mean absolute Ep value in control group $(924.7 \pm 12.5)$ was significantly higher than in group II (796.8 \pm 7.4$)$, group III $(828.0 \pm 15.0)$, group IV (778.4 \pm 7.6), and group V (793.8 \pm 9.0$)$. The mean absolute Icorr value in control group $(0.17 \pm 0.02)$ was significantly lower than in group II $(0.31 \pm 0.02)$, group III $(0.23 \pm 0.02)$, group IV $(0.47 \pm$ $0.03)$, and group $\mathrm{V}(0.33 \pm 0.02)$. Within the base metal alloy groups at Ecorr, groups III and $\mathrm{V}$ were significantly higher than the other study groups. At Eb, Ep, and Icorr, group III was significantly higher than the other study groups.

\section{DISCUSSION}

Metal-ceramic restorations and cast partial dentures that are largely exposed to conducive oral environment may exhibit greater corrosion tendencies. The concern about the corrosion tendency has greatly intensified in recent years after the introduction of several base metal alloys. With the advent of various commercially available $\mathrm{NiCr}$ alloys in day-to-day practice, the scientific evaluation of corrosive behavior during the process of development of new dental alloys is highly recommended.

\section{Corrosion Potential}

Corrosion potential(Ecorr) indicates the steady-state potential of an alloy where oxidation and reduction reaction are in equilibrium. The corrosion potential shifted toward the more positive direction with a greater shift in the beginning and then attained a steady state value after a lapse of 8 to 10 minutes in both study group and control group. This displacement of corrosion potential toward a more positive direction for all alloy samples could be due to the existence of a more protective surface oxide layer. ${ }^{4}$ The value of Ecorr (-219.5; Table 3) of the control group was significantly higher than the study group,

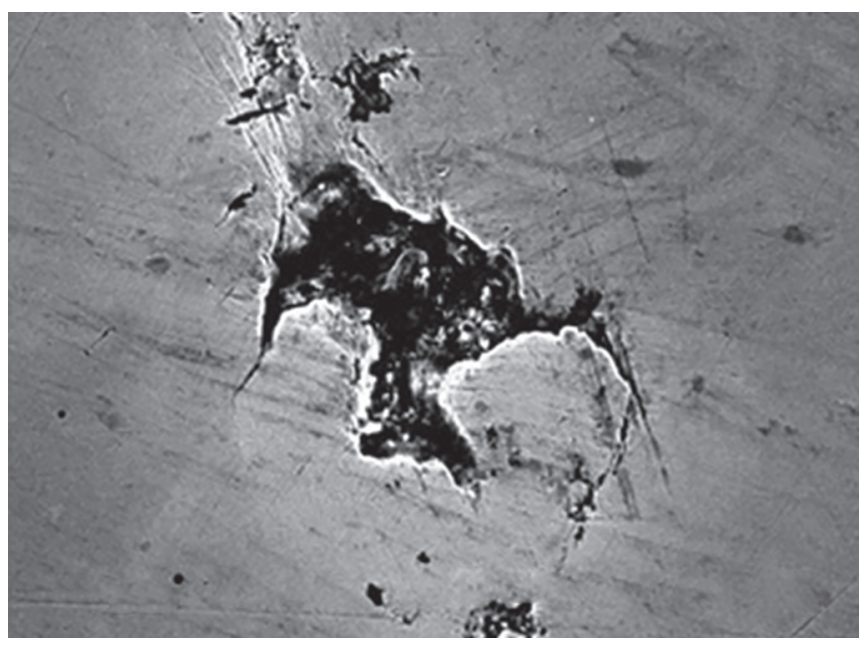

Fig. 6: Scanning electron microscope photomicrograph of group $\mathrm{V}$

Table 3: Corrosion potential (Ecorr)

\begin{tabular}{llll}
\hline & & Standard \\
Groups & Mean \pm SD & error & Median (range) \\
\hline I & $-219.5 \pm 12.1$ & 3.8 & $-219(-205$ to -242$)$ \\
II & $-161.6 \pm 9.4$ & 3.0 & $-163.5(-140$ to -171$)$ \\
III & $-128.3 \pm 12.0$ & 3.8 & $-131.5(-102$ to -144$)$ \\
IV & $-155.4 \pm 12.6$ & 4.0 & $-156(-134$ to -175$)$ \\
V & $-119.3 \pm 13.4$ & 4.3 & $-117(-101$ to -142$)$ \\
\hline SD: Standard deviation & &
\end{tabular}

which is mainly attributed to the high inertness of the noble alloy. Within the study alloy groups, the value of Ecorr of group V (-119.3) was significant than the other study groups which could be because of the presence of silica $(2 \%)$ which reduces the oxidation of an alloy, which goes in accordance to the studies done by Gregory ${ }^{5}$ and Lewis, ${ }^{6}$ and the mean corrosion potential (Ecorr) of group IV (-155.4) was significant than groups II (-161.6) and III $(-128.3)$ which could be due to presence of $1.5 \%$ of silica.

\section{Breakdown Potential}

Breakdown potential $(\mathrm{Eb})$ indicates the potential at which the oxide layer of an alloy breaks down. The value of $\mathrm{Eb}$ of group I (1016.2) was significantly higher than other study groups, indicating that the high noble alloy demonstrated the highest Eb value followed by groups III, II, $\mathrm{V}$, and finally, group IV alloys. This value is in accordance with Marek $^{7}$ who concluded that noble alloys exhibit a single-phase uniform homogenization, grain refinement, and high thermodynamic stability. The value of $\mathrm{Eb}$ of group III (800.1; Table 4) was significantly higher than other study groups, which could be because of the presence of $11 \% \mathrm{Mo}, 25 \% \mathrm{Cr}$, and $1.0 \%$ of manganese which are responsible for increase in $\mathrm{Eb}$ value. This finding goes in accordance with Pourbaix, ${ }^{8}$ who reported that a small addition of manganese increases the corrosion resistance of an alloy. It is also reported that the molybdenum plays 
Evaluation of Corrosive Behavior of Four NiCr Alloys

\begin{tabular}{|c|c|c|c|}
\hline \multicolumn{4}{|c|}{ Table 4: Breakdown potential (Eb) } \\
\hline Groups & Mean $\pm S D$ & $\begin{array}{l}\text { Standard } \\
\text { error }\end{array}$ & Median (range) \\
\hline I & $1016.2 \pm 9.5$ & 3.0 & $1017(1002-1028)$ \\
\hline II & $738.4 \pm 8.5$ & 2.7 & $739.5(725-755)$ \\
\hline III & $800.1 \pm 6.7$ & 2.1 & $800.5(784-808)$ \\
\hline IV & $672.3 \pm 12.7$ & 4.0 & $675.5(650-686)$ \\
\hline V & $723.8 \pm 5.8$ & 1.8 & $725.5(715-730)$ \\
\hline
\end{tabular}

SD: Standard deviation

an important role in grain refinement. ${ }^{1}$ Group IV alloy had a low (Eb) value (672.3), which could be because of a decrease in molybdenum $(9.5 \%)$ and chromium $(22.5 \%)$ content and absence of manganese in the alloy. The values of Eb of group II (738.4) alloy and group V (723.8) alloy were almost similar, but there is a slight increase in $\mathrm{Eb}$ value of group II, which could be because of higher content of chromium (26\%) when compared with group V (23\%).

\section{Repassivation Potential}

Repassivation potential (Ep) is the potential at which the reformation of the passive oxide layer which helps in corrosion resistance of an alloy occurs. The value of Ep of group I (924.7; Table 5) was significantly higher than the study groups. This can be attributed to the presence of gold and platinum which are highly corrosion resistant and possess positive electrode potential indicating their passive activity in electrolyte solutions. Within the four study groups, the value of Ep of group III $(828 \mathrm{Mv})$ was significantly higher than other study groups, showing little or no hysteresis. This may be due to the higher percentage of molybdenum (11\%), followed by groups $\mathrm{V}$ (793.8), II (796.8), and IV (778.4).

\section{Corrosion Current Density}

Corrosion current (Icorr) determines the corrosion rate of an alloy. The value of Icorr of high noble alloy (0.17; Table 6) was significantly higher than the study groups. This indicates that those high noble alloys are more resistant to corrosion because of its superior mechanical and physical properties. The value of Icorr of group III (0.23) was lower, indicating that group III was more resistant to corrosion. The value of Icorr of group IV

Table 6: Corrosion current (Icorr)

\begin{tabular}{llll}
\hline Groups & Mean \pm SD & $\begin{array}{l}\text { Standard } \\
\text { error }\end{array}$ & Median (range) \\
\hline I & $0.17 \pm 0.02$ & 0.006 & $0.165(0.15-0.20)$ \\
II & $0.31 \pm 0.02$ & 0.007 & $0.30(0.29-0.36)$ \\
III & $0.23 \pm 0.02$ & 0.005 & $0.22(0.21-0.26)$ \\
IV & $0.47 \pm 0.03$ & 0.009 & $0.465(0.44-0.52)$ \\
V & $0.33 \pm 0.02$ & 0.006 & $0.325(0.31-0.38)$ \\
\hline
\end{tabular}

SD: Standard deviation
Table 5: Repassivation potential (Ep)

\begin{tabular}{llll}
\hline Groups & Mean \pm SD & $\begin{array}{l}\text { Standard } \\
\text { error }\end{array}$ & Median (range) \\
\hline I & $924.7 \pm 12.5$ & 3.9 & $925(905-939)$ \\
II & $796.8 \pm 7.4$ & 2.3 & $796.5(784-806)$ \\
III & $828.0 \pm 15.0$ & 4.8 & $825(805-855)$ \\
IV & $778.4 \pm 7.6$ & 2.4 & $781(765-789)$ \\
V & $793.8 \pm 9.0$ & 2.9 & $797(775-802)$ \\
\hline
\end{tabular}

SD: Standard deviation

was highest (0.47), indicating that this group was more prone to corrosion which could be due to the reduced amount of chromium (22.2\%) and molybdenum (9.5\%) contents in the alloy which play an important role in their corrosive behavior even at higher temperatures. ${ }^{9}$

\section{Accelerated Leaching Study}

There were no specific ions released during the accelerated leaching study in the control group. The results represent the relative stability and nobility of these alloys. The results of this study confirmed the observation by Wataha et $\mathrm{al}^{10}$ and Schalmz ${ }^{11}$ who all stated that the gold and platinum ion release is always below detection limits. When the study groups were subjected to ICP-MS, there were no specific ions in the test solutions at Ecorr. However, at Eb (breakdown potential), the average value of nickel and chromium ions released were 60 to 68 and 50 to $53 \mu \mathrm{g} / \mathrm{cm}^{2}$ respectively, after 1 hour and approximately 1440 and $1200 \mu \mathrm{g} / \mathrm{cm}^{2}$ after 24 hours, which is almost three times greater than the dietary intake of nickel and chromium ions (normal 400 and $240 \mu \mathrm{g}$ in about 24 hours). ${ }^{12}$ The exaggerated values in this study could be attributed to the accelerated leaching which was done intentionally to determine the specific ion release. However, in clinical conditions, these values may be lower as they are not subjected to an accelerated leaching process. Further studies may be done to assess these values in clinical conditions where these alloys may be subjected to accelerated leaching.

\section{Scanning Electron Microscope Observation}

The morphology of the pit of corroded alloy samples was evaluated in terms of pit dimensions and depth. ${ }^{13}$ The surface topography of control group alloy revealed no pit formation. The pit dimensions of NiCr alloys indicate their potential to corrosion. The pit size was greater in group IV, indicating that they are more prone to corrosion, followed by groups V, II, and III, which were least prone to corrosion.

\section{CONCLUSION}

Within the limitations of this study, it could be concluded that high noble alloys are more resistant to corrosion 
than the base metal alloys. Within the base metal alloy study groups, group III was more resistant to corrosion, followed by groups II, V, and IV. Although both nickel and chromium ions were released during the corrosion process, the percentage of nickel ions was relatively higher than chromium ions.

\section{REFERENCES}

1. Anusavice, KJ. Phillipes science of dental materials. 11th ed. Philadelphia (PA): WB Saunders; 2003. p. 573.

2. Winkler S, Morris HF. Changes in mechanical properties and microstructure following heat treatment of a nickelchromium base alloy. J Prosthet Dent 1984 Dec;52(6): 821-827.

3. Abfraction E. The glossary of prosthodontic terms. J Prosthet Dent 2005 Jul;94(1):10-92.

4. Roach MD, Wolan JT, Parsell DE, Bumgardner JD. Use of photoelectron spectroscopy and cyclic polarization to evaluate the corrosive behavior of six nickel-chromium alloys before and after porcelain-fused-to-metal firing. J Prosthet Dent 2000 Dec;84(6):623-634.
5. Gregory DO. Nickel-chromium alloys in casting. Miss Dent Assoc J 1982 Winter;38(4):18-20.

6. Lewis AJ. Changes in composition of a nickel based partial denture casting upon fusion and casting. Aust Dent J 1975 Feb;20(1):14-18.

7. Marek, M. Corrosion in a biological environment. In: Lang BR, Morris HF, Razzoog ME, editors. Biocompatibility, toxicity, and hypersensitivity to alloy systems used in dentistry. Ann Arbor (MI): The University of Michigan School of Dentistry; 1986. pp. 103-122.

8. Pourbiax M. Electrochemical corrosion of metallic biomaterials. Biomaterials 1984 May;5(3):122-134.

9. Agarwal, DC. Proceedings of the 12 th international corrosion congress. Houston (TZ): NACE; 1993. p. 1226.

10. Wataha JC, Craig RG, Hanks CT. The release of elements of dental casting alloys into the cell-culture medium. J Dent Res 1991 Jun;70(6):1014-1018.

11. Schmalz G. Biocompatibility testing of dental restorative materials. Clin Oral Investig 1997 Dec;1(4):154-162.

12. Brune D. Metal release from dental biomaterials. Biomaterials 1986 May;7(3):163-175.

13. Rajendran N. Evaluation of high Ni-Cr-Mo alloys for the construction of sulphur dioxide scrubber plants. J Mater Sci Eng Perform 1996 Feb;5(1):46-50. 